\title{
Plant Receptor-Like Serine Threonine Kinases: Roles in Signaling and Plant Defense
}

\author{
Ahmed J. Afzal, ${ }^{1}$ Andrew J. Wood, ${ }^{2}$ and David A. Lightfoot ${ }^{3}$ \\ ${ }^{1}$ Department of Molecular Biology, Microbiology and Biochemistry, ${ }^{2}$ Department of Plant Biology, and ${ }^{3}$ Center \\ for Excellence in Soybean Research, Teaching, and Outreach, Department of Plant, Soil, and Agricultural Systems, \\ Southern Illinois University, Carbondale, IL 62901, U.S.A.
}

Submitted 3 May 2007. Accepted 14 January 2008.

Plants are hosts to a wide array of pathogens from all kingdoms of life. In the absence of an active immune system or combinatorial diversifications that lead to recombinationdriven somatic gene flexibility, plants have evolved different strategies to combat both individual pathogen strains and changing pathogen populations. The receptor-like kinase (RLK) gene-family expansion in plants was hypothesized to have allowed accelerated evolution among domains implicated in signal reception, typically a leucine-rich repeat (LRR). Under that model, the gene-family expansion represents a plant-specific adaptation that leads to the production of numerous and variable cell surface and cytoplasmic receptors. More recently, it has emerged that the LRR domains of RLK interact with a diverse group of proteins leading to combinatorial variations in signal response specificity. Therefore, the RLK appear to play a central role in signaling during pathogen recognition, the subsequent activation of plant defense mechanisms, and developmental control. The future challenges will include determinations of RLK modes of action, the basis of recognition and specificity, which cellular responses each receptor mediates, and how both receptor and kinase domain interactions fit into the defense signaling cascades. These challenges will be complicated by the limited information that may be derived from the primary sequence of the LRR domain. The review focuses upon implications derived from recent studies of the secondary and tertiary structures of several plant RLK that change understanding of plant receptor function and signaling. In addition, the biological functions of plant and animal RLK-containing receptors were reviewed and commonalities among their signaling mechanisms identified. Further elucidated were the genomic and structural organizations of RLK gene families, with special emphasis on RLK implicated in resistance to disease and development.

Plants, like their animal counterparts, suffer ingress, infection, or toxicity by pathogenic organisms from all known kingdoms

Current address for A. Afzal: Department of Horticulture and Crop Science, The Ohio State University, 350 Kottman Hall, 2021 Coffey Road, Columbus, OH 43210, U.S.A.

Corresponding author: D. A. Lightfoot; E-mail: ga4082@siu.edu

* The $\boldsymbol{e}$-Xtra logo stands for "electronic extra" and indicates that two supplemental figures are published online. of life (Baker et al. 1997). Plant proteins that confer resistance to pathogens share striking motif, domain, and structural similarities. Such widespread similarity has derived from both evolutionary conservation and convergence that suggest that common signaling events underlie defense cascades.

The resistance or susceptibility to infection of a particular plant genotype within a species is determined by intertwined layers of defense, including both constitutive barriers and inducible reactions (Thordal-Christensen 2003). The control of the inducible reactions places importance upon understanding the mechanisms by which plants both perceive environmental signals and transmit them through the cellular machinery to activate adaptive responses.

Plants lack extracellular antibodies and specific cells that defend against pathogen attack. Nevertheless, they have developed remarkable strategies to detect and adapt to environmental cues by the use of a wide array of receptors at the cell surface and within cells (Gomez-Gomez and Boller 2002). Initial steps in a general signal transduction cascade include perception of a primary extracellular signal or set of signals that change the interaction partners of the receptor. That multifactor binding event is followed by transmission of secondary signals through the plasma membrane. The accumulation of intracellular signaling molecules causes the induction of specific phosphorylation and dephosphorylation cascades. In combination, the metabolic changes result in specific plant responses that include the activation of cadres of genes involved in particular defense responses or alterations to developmental processes (Gachomo et al. 2003).

Interestingly, signal perception through cell surface receptors is a common feature in both plants and animals (Fig. 1). In plants, a diverse group of receptors receive signals from the environment (Gomez-Gomez and Boller 2002). Some of the receptor classes (Fig. 2) such as the nucleotide-binding site leucine-rich repeat (NBS-LRR) receptors and histidine kinase receptors, can mediate responses to organic chemicals such as the hormones ethylene and cytokinin (Bleecker and Kende 2000; Higuchi et al. 2004). The receptor class that is the focus of this review, the receptor serine threonine kinases (RSTK), interact with other proteins to effect a wide array of processes ranging from disease resistance and developmental regulation to self- versus non-self-recognition (Goring and Walker 2004). Proteins involved in plant development or defense fall mainly into two broad groups. The major group contains members that belong to the NBS-LRR class. These encode intracellular proteins with LRR receptor motifs combined with a predicted nucleotide binding site sequence (Fig. 1; DeYoung and Innes 
2006). Members of the second group encode transmembrane proteins; with amino-terminal extracellular domains implicated in elicitor recognition and protein-protein interactions; and a carboxyl-terminus intracellular kinase domain involved in signal transduction (Morillo and Tax 2006). These receptor protein kinases (RPK) are strikingly similar in domain organization to the animal receptor tyrosine kinase protein family (Yamamoto and Knap 2001). However, the plant and animal proteins are not homologous and may have arisen by convergent evolution and independent domain fusions (Ingram and Waites 2006).

\section{RPK.}

RPK can be divided into three major subclasses according to different substrate specificities among the kinase domains (Fig. 2). The subclasses are the receptor tyrosine kinases (RTK) that are implicated in the phosphorylation of tyrosine residues, serine/threonine kinases (STK) that phosphorylate serine and threonine residues and histidine kinases that phosphorylate histidine residues (Becraft 2002) (Fig. 2). The predominant RPK present in animals is the RTK, whereas the TGF $\beta$ family members represent the only known STK members present in animals. RPK found in plants include receptor histidine kinases (RHK) and RSTK. Examples of RHK include the ethylene receptor ETR1 (Bleecker and Kende 2000) and the cytokinin receptor CRE1 (Inoue et al. 2001). The majority of RPK in plants are type Ia membrane proteins containing a predicted extracellular signal sequence, an LRR, a single pass transmembrane helix, and a cytoplasmic kinase domain with the serine/threonine consensus sequence (Hardie 1999). Variants within the RPK class include $\mathrm{N}$ terminal-LRR extracellular receptors with a C-terminal membrane anchor and proteins

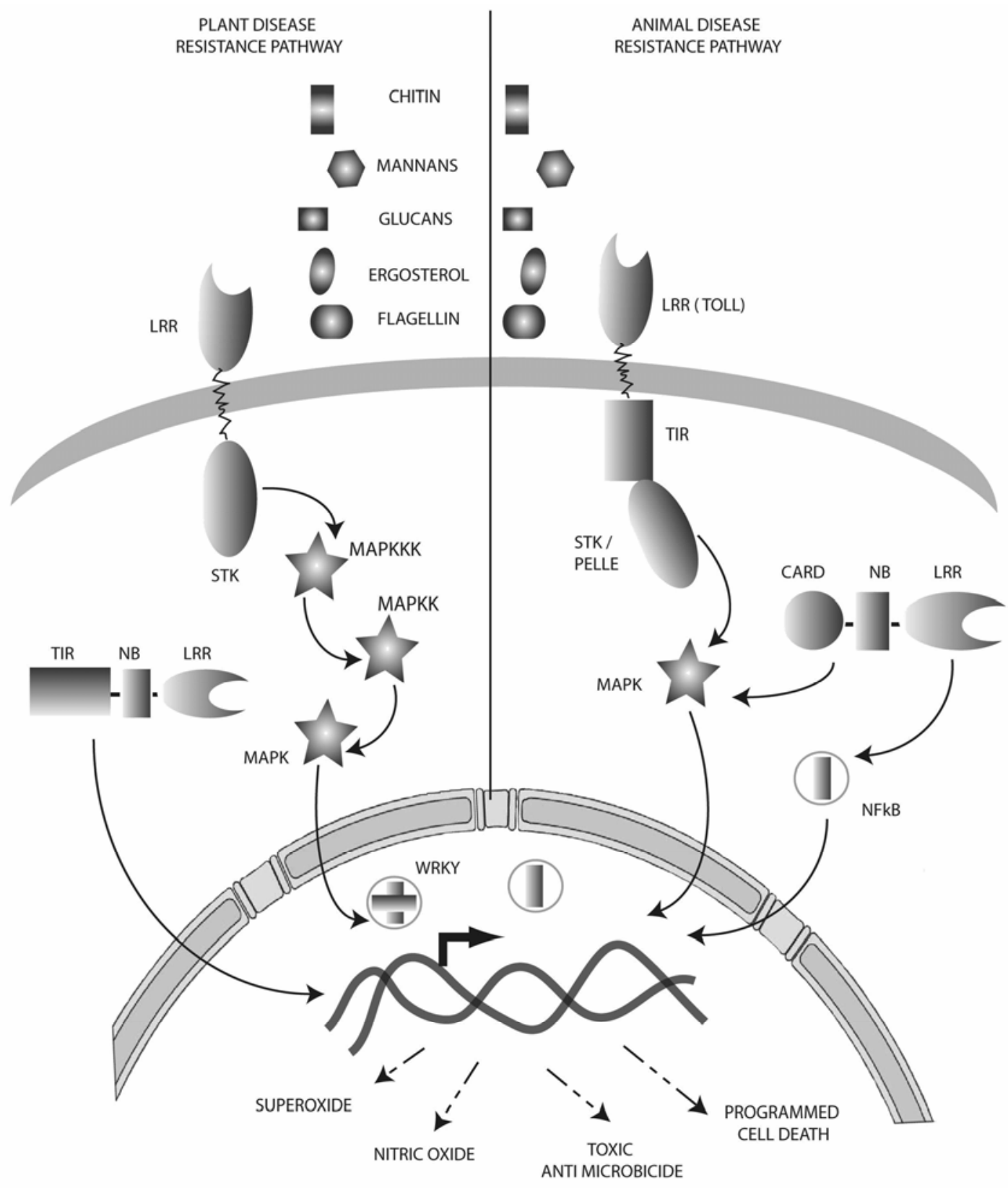

Fig. 1. Similarities in modes of action between plant (left) and animal (right) receptor-like kinases. Plants and animals recognize similar pathogen-associated molecular patterns (PAMPs) and use extracellular leucine-rich repeat (LRR) receptors for elicitor recognition, serine/threonine kinases (STKs) for downstream processing, and mitogen-activated protein kinases (MAPKs) for signal relay. Both elicit similar defense responses such as generation of nitric oxide and superoxide, production of antimicrobial compounds, and the hypersensitive response or programmed cell death. 
with a kinase domain lacking any of the predicted ligand-binding domains. Receptor-like kinases (RLK) fall into a broad family known as the RLK/Pelle family. IRE1-like proteins are the only other known serine/threonine receptor kinases present in plants (Fig. 2) (Bögre et al. 2003). They are part of the AGC kinase family (cyclic pyrimidine or phospholipid-dependent protein kinase $\mathrm{C}$ ). In addition to the receptor kinase domain, the IRE proteins characteristically contain a ribonuclease domain as well as a luminal sensor domain (Oyama et al. 2002). IRE1-encoding genes are not closely related to the receptor kinase/Pelle family, suggesting that the two receptor configurations arose independently (Shiu and Bleecker 2003). Two plant RPK appear to be dual-specificity kinases and cannot be assigned to one group or the other. PRK1, which is a pollenexpressed receptor kinase, autophosphorylates on tyrosine and serine residues ( $\mathrm{Mu}$ et al. 1994). Somatic embryogenesis receptor-like kinase (SERK) phosphorylates threonines, serines, and tyrosines (Fig. 2; Shah et al. 2001b).

\section{Functions of plant RLK proteins.}

Plant RLK functions can be classified into two major categories (Shiu et al. 2004). The first functional category consists of kinases involved in cell growth and development. Examples from Arabidopsis thaliana were involved in floral organ abscission (HAESA, Jinn et al. 2000), the regulation of cell growth (BRI1; Li and Chory 1997), and meristem development (CLAVATA1; Clark et al. 1997). The second functional category includes RLK proteins involved in plant-pathogen interaction and defense responses such as the rice bacterial blight resistance gene product XA21 (Song et al. 1995) and $A$. thaliana flagellin perception gene FLS2 (Gomez-Gomez and Boller 2000). Additional RLK proteins that do not fall into the two major classes include proteins implicated in symbiosis such as NORK/SYMRK and HAR1 (Krusell et al. 2002), S receptor kinases (SRK) contributing to self incompatibility (Kachroo et al. 2001), and SRH5, a protein involved in the control of di-nitrogen fixation (Vinagre et al. 2006). Structures of the LRR domains are hypothesized to correlate with the functional categories. For LRR domains to be involved in the control of development (e.g., the sensing of cell size) in relation to extracellular ligand concentrations or ratios should require separate physicochemical properties for the domain. In disease resistance, we hypothesize that the domain will be required to bind several ligands and integrate the binding to an

\section{Protein classes in development and disease}

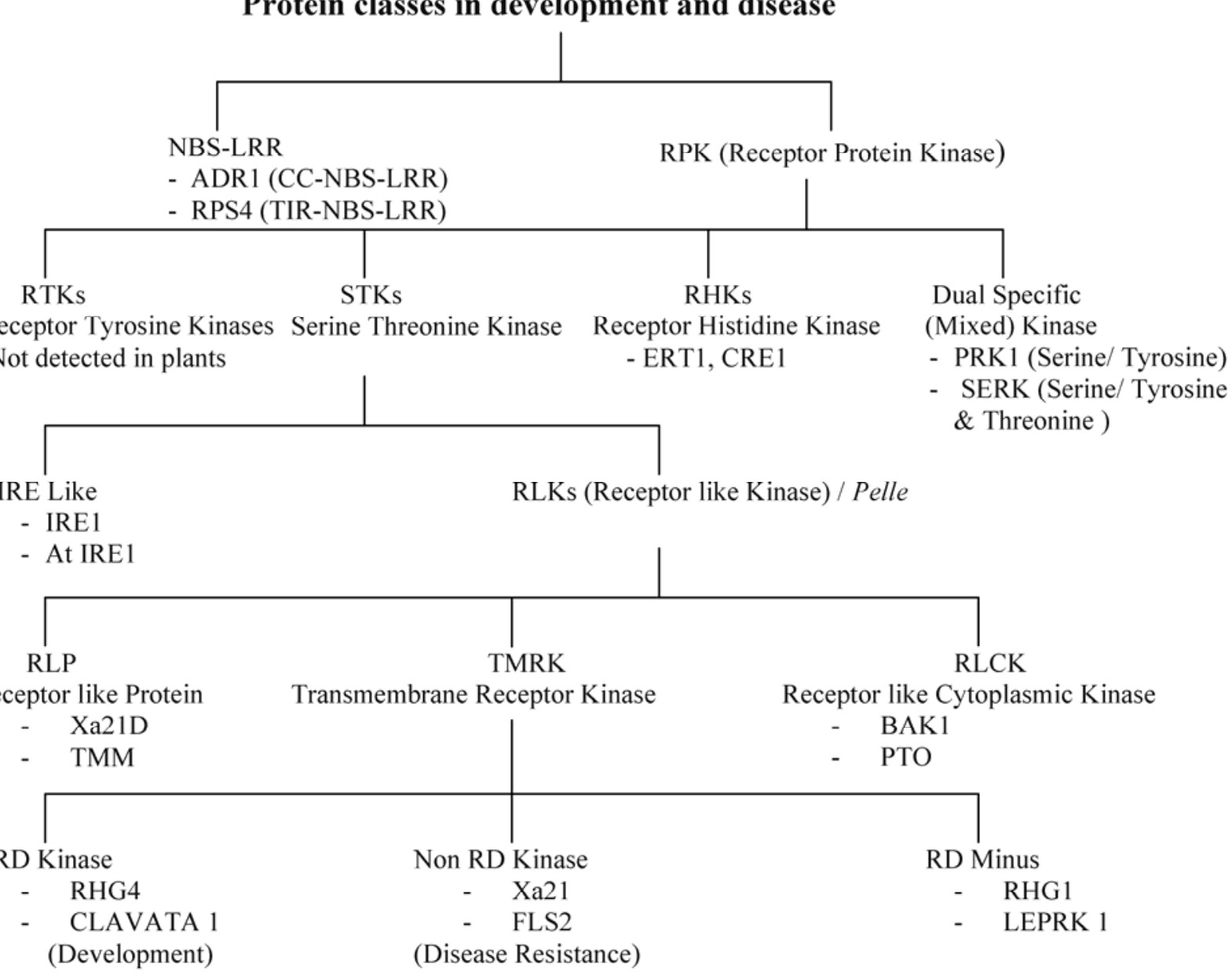

Fig. 2. Classification scheme for receptor protein kinases (RPKs) involved in plant development and disease resistance. Plant proteins containing leucine-rich repeat (LRR) receptors can be divided into two major categories: the nucleotide-binding site (NBS)-LRR type (DeYoung and Innes 2006) and RPKs. RPKs can be further divided into three major subclasses according to different substrate specificities in the kinase domains. The receptor tyrosine kinases (RTKs) phosphorylate tyrosine residues, serine/threonine kinases (STKs) phosphorylate serine and threonines, and histidine kinases phosphorylate histidine residues (Becraft 2002). Two plant RPKs, PRK1 (Mu et al. 1994) and somatic embryogenesis receptor like kinase (SERK) (Shah et al. 2001b) appear to be dualspecificity kinases and cannot be assigned to one group or the other. Receptor serine threonine kinases (RSTKs) fall into a broad family known as the receptor-like kinase (RLK)/Pelle family. IRE1-like proteins are the only other known serine/threonine receptor kinases present in plants (Bögre et al. 2003). The RLKs can be subdivided into TMRKs, receptor-like cytoplasmic kinases (RLCKs) and receptor-like proteins (RLPs) (Shiu and Bleecker 2003). TMRK can be further grouped into RD kinases, non-RD kinases, and RD-minus kinases. 
appropriate response. In agreement with this hypothesis, modeling the LRR domains of proteins involved in disease resistance shows many regions that are unstructured in the absence of ligand (Afzal 2007). However, it must be noted that functional classification of RLK on the basis of structure may turn out to be more complex due to the cross talk between disease and developmental pathways or due to the recognition of multiple ligands by a signal receptor. For instance, BRI1-associated receptor kinase 1 (BAK1) previously was shown to be involved in plant developmental regulation (Eckardt 2005); however, recent data suggests that it also has a role in the initiation of innate immunity by positively regulating pathogenassociated molecular pattern (PAMP) signaling (Chinchilla et al. 2007). BAK1 may function as a co-receptor leading to regulation of various disease and defense-related receptors (Chinchilla et al. 2007). Similarly, ERECTA, an LRR kinase known to be involved in ovule development (Pillitteri et al. 2007), also is involved in resistance to bacterial wilt (Godiard et al. 2003).

\section{RLK as a plant-specific adaptation.}

The RLK-encoding gene family first was found in Zea mays 17 years ago (Walker and Zhang 1990). Since then, thousands of RLK genes have been identified from many different plant species. The monocot-dicot common ancestor may have contained more than 440 RLK/Pelle members (Shiu et al. 2004). In A. thaliana, the RLK gene family contained more than 600 members, constituted $60 \%$ of all kinases present, and encompassed $2.5 \%$ of the coding region of the A. thaliana genome (Shiu and Bleecker 2003). In contrast, none of the known fungal genomes contained recognizable RLK/Pelle members. Equally, basal eukaryotes and many animals contain only one to six members, all with known functions. In sharp contrast, all plant RLK belong to large gene families $(>1,000$ members in Oryza sativa; Shiu et al. 2004), most with functions yet to be determined. The RLK family may have originated in a common ancestor of all eukaryotic genomes but was lost from a low copy number state in the progenitor of the fungal genomes. Alternately, the gene families may have arisen polyphyletically and have not persisted in fungal genomes. Speaking to this, plant genome analysis has inferred at least four large-scale duplication events (Vision et al. 2000) that may have contributed to the RLK gene number present in Arabidopsis today (Shiu and Bleecker 2003). The RLK gene family continued to expand after the Arabidopsis-rice split (Shiu and Bleecker 2003) but, interestingly, further expansion was restricted to subfamilies within the set of RLK genes involved in disease resistance, such as the legume lectin (L-LEC) and the LRR subfamily 1a (LRR-1a), not those implicated in the control of development.

Lineage-specific expansions were evident in addition to the large-scale genome wide duplications inferred. For instance, the LRR-XII subfamily (that includes the gene $X a-21$ ) has more than 150 members in rice but only 6 in A. thaliana (Shiu and Li 2004). Evidently, most lineage-specific expansions were not coordinated between lineages but, rather, reflect different selection pressures during the evolution of the progenitors of rice (that adapted to tropical environments) and Arabidopsis (that adapted to temperate zones). In Arabidopsis, both tandem and large-scale duplication have contributed to the large number of RLK/Pelle members (Shiu et al. 2004). However, in rice, only tandem duplications have been shown to play a major role in RLK/Pelle expansion. As a consequence, the RLK gene family has contributed considerably to the gene number difference between Arabidopsis and rice. It should be noted that the larger RLK/Pelle family in rice was not a consequence of the larger expansion of the rice genome (Shiu et al. 2004).

\section{Lineage-specific RLK expansion.}

In silico analysis has suggested that the degree of lineagespecific expansion of the RLK gene family in rice and Arabidopsis in both the disease and development categories was significantly different (Shiu et al. 2004). None of the RLK involved in developmental control in either rice or Arabidopsis were found in tandem clusters showing a lack of recent expansions. Therefore, transcription factors rather than signaling molecules may have been the major factors involved in adaptations in developmental regulation in the last 80 million years (Doebley and Lukens 1998). However, only in rice are RLK involved in resistance or defense response found as tandem clusters due to tandem duplications. That seems to be the major mechanism for the recent expansion in rice. These tandem duplications eventually may result in gene fusions providing novel ways to recognize extracellular signals such as pathogen effectors (Shiu et al. 2004).

The lack of expansion in genes that control major events in development also has been observed for mouse and human; for example, among the tyrosine kinase family of genes. Here, too, a 1:1 ratio exists between mouse and their human counterparts (Young et al. 2002). Another interesting parallel exists between plants and mammals. In mammals, the large gene families such as the mammalian olfactory lobe receptors (Young et al. 2002) and taste receptors have expanded differently among species (Shi et al. 2003). In both cases of differential expansion, the perception of diverse extracellular signals is involved.

\section{Examples of RLK.}

RLK involved in signaling mainly recognize exogenous elicitor complexes that activate defense-related pathways. For developmental processes, the stimulus is usually endogenous (Brand et al. 2000). CLAVATA-like gene-family proteins may contain as many as 20 members (Sharma et al. 2003). The CLV1/CLV2 receptor complex and the CLV3 ligand each are members involved in meristem development and, more specifically, in meristem-size homeostasis. Loss of function in any of the three best-characterized CLAVATA-like genes (CLV1, CLV2, and CLV3) causes a progressive enlargement of the shoot meristem as stem cell proliferation surpasses differentiation (Clark et al. 1997). Genetic analysis showed that the proteins encoded by these genes were part of a common pathway, involved in regulation of meristem development (Clark et al. 1997; Haffani et al. 2004). Some biochemical evidence points toward an interaction between the CLV3 ligand complex (possibly indirectly) and the CLV1/CLV2 protein heterodimer that consequently undergoes phosphorylation (Jeong et al. 1999; Trotochaud et al. 1999). Activation of the kinase domain was proposed to trigger the assembly of a functional signaling complex that also contained a kinase-associated protein phosphatase (KAPP) and a Rho-like GTPase (ROP; Trotochaud et al. 1999). Activation of ROP, in turn, activated an as yet unknown cascade that relayed the signal from cytosol to the nucleus. Downstream signaling may involve the WUSCHEL (WUS) homeodomain transcription factor (Sharma et al. 2003). The WUS transcription factor promoted the formation and maintenance of meristem cells.

In most cases of receptor binding though, the interaction with the ligand is an extracellular event. For example, in $A$. thaliana, the FLS2 receptor involved in innate immunity binds certain epitopes of bacterial flagellin proteins (Chinchilla et al. 2006; Gomez-Gomez and Boller 2000). FLS2 encodes a receptor kinase with 28 extracellular LRR. Interaction of bacterial flagellin (elicitor) with the plasma-membrane-localized FLS2 receptor causes rapid ion flux that, in some manner, induces activation of the kinase domain which, in turn, is directly 
or indirectly associated with activation of downstream signals and, ultimately, the plant's defense responses (Chinchilla et al. 2006; Haffani et al. 2004). The eventual cellular responses include the production of antimicrobial phytoalexins, ethylene, and salicylic acid; the production of reactive oxygen species (ROS); and the activation of a wide array of defense-related genes (Tierens et al. 2002) (Fig. 1). However, the link to perception of ligands by RLK remains to be elucidated.

\section{Receptor-like proteins.}

Two-thirds of the RLK family members are transmembrane receptor kinases (Shiu and Bleecker 2003) and the remaining third are nonreceptor kinases (receptor-like cytoplasmic kinases) or receptor-like proteins (RLP). RLP resemble extracellular domains of RLK but lack the internal kinase domain. More than half of the RLP present in the Arabidopsis genome are composed of varying numbers of LRR but only a few of these have been associated with a functional role inside the cell. For instance, TMM (too many mouths) is an LRR receptor-like transmembrane protein involved in stomatal patterning (Nadeau and Sack 2002). It is not known whether this RLP is functionally associated with another RLK or functions on its own. XA21D, an RLP, is a paralog of the rice $\mathrm{Xa21}$ gene that encodes another RLK. XA21-D confers partial disease resistance to bacterial blight, perhaps by forming heterodimers with a receptor kinase LRR (Wang et al. 1998). Phylogenetically, most of the LRR containing RLP appear more similar to one another than they are to the LRR in RLK. A significant num- ber of these RLP are located within a large RLK cluster, suggesting the possibility that RLP were derived from or had given rise to RLK with similar extracellular domains (Shiu and Bleecker 2003). Another RLP mentioned previously, CLV2, also lacks a cytoplasmic sequence motif. The protein attains active function through the formation of a membrane-bound receptor protein complex with CLV1 LRR-receptor kinase (Fig. 3F; Jeong et al. 1999).

\section{Receptor-like cytoplasmic kinases.}

Receptor kinases lacking the extracellular domain are termed receptor-like cytoplasmic kinases (RLCK; Goring and Walker 2004). M locus protein kinase (MLPK) involved in self incompatibility in Brassica spp. belongs to the RLCK class. Upon binding of the self-incompatibility pollen ligand to the SRK, MLPK is recruited to the activation complex, resulting in a series of events leading to rejection of the self pollen. In another variation, plant receptor kinases work with nonreceptor kinases ( $\mathrm{Li}$ et al. 2002). BRI1, a receptor kinase, detects the plant hormone brassinosteroid in A. thaliana. A required step in brassinosteroid signaling is interaction of BRI1 with a RLCK named BAK1 (Fig. 3E).

The kinase domain alone in certain cases has been implicated both in elicitor recognition and ser/thr phosphorylation (Bogdanove and Martin 2000). PTO, a cytoplasmic serine/ threonine kinase, confers race-specific resistance to Pseudomonas syringae by recognition of avrPTO. PTO does not contain a known ligand binding motif but is involved in both elici-

\section{Model for ligand -receptor recognition in plany receptor like kinases}

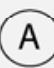

| $X B 3$ is required for stability of XA21.

Upon pathogen infection, XB3 is phophorylated by XA21. This serves as a defense signal |

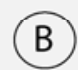
| Arabidopsis |CrRLK1 from |PTO a thaliana RLK5 is Catharanthus sp cytoplasmic shown to trans shows auto- Ser thr kinase phosphorylate phosphorylation is involved in presumably suggesting resistance after hetero absence of to Pseudomonas dimer formation, oligomerization, syringae AvrPTO

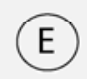

Brassinosteroid signaling involves interaction of BRI1 with a RLCK (BAK1)

.

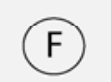

| CLV3 interacts with | Indirect recognition CLV1/CLV2.

(guard hypothesis)

CLV2 is a RLP |cleavage / modification

lacking a

cytoplasmic kinase of "guardee" by the elicitor results in the activation of the R protein

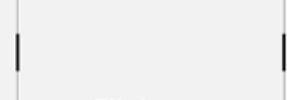

liond
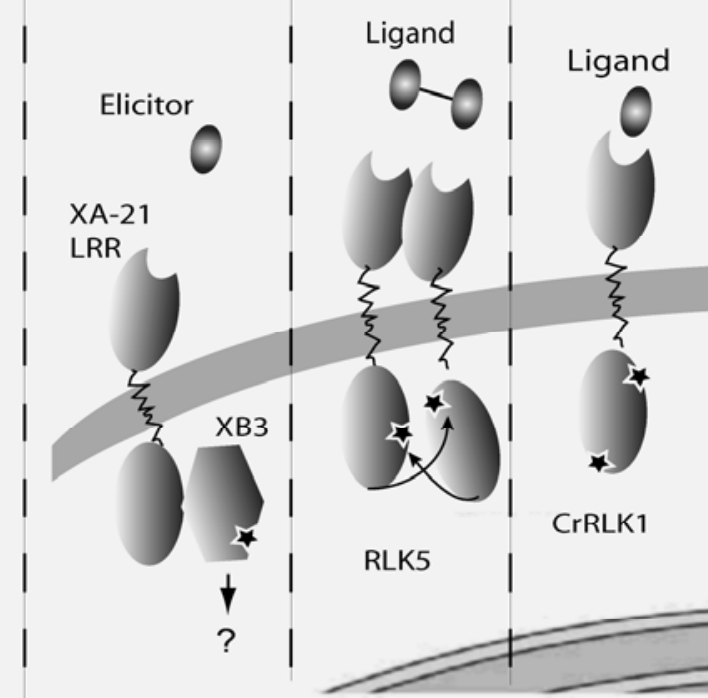
1
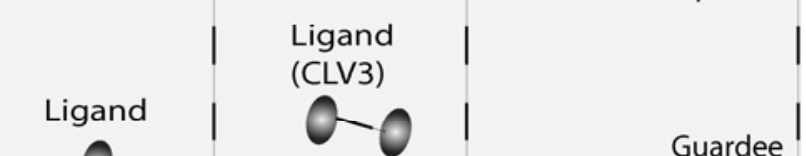
(1) 
tor recognition and phosphorylation (Fig. 3D). Additionally, the stem rust-resistant gene rpgl from barley encodes a ser/thr kinase which does not contain a strong membrane-targeting motif, suggesting a mechanism of action similar to the protein encoded by the tomato Pto gene (Brueggeman et al. 2002). Moreover, RPG1 contains two tandem kinase domains which is a novel structure for proteins involved in plant disease resistance.

\section{RLK structure.}

The RLK/Pelle family in A. thaliana can be divided into 45 subfamilies based on three distinct criteria: presence and identity among the extracellular domains, phylogenetic relationships inferred for the kinase domains, and intron locations and intron phases (Shiu and Bleecker 2003; Shiu et al. 2004). RLK vary greatly in their sequence identity and domain organization among the extracellular domains. A variety of extracellular domains are present in RLK. The extracellular domains in RLK have been classified into 15 types: CRINKLY4-like, Ctype lectin-like, CrRLK1-like, DUF26-like, extensin-like, legume (L)-lectin-like, LRK10-like, LRR-like, LysM-like, PERK-like, RKF3-like, S-domain-like, thaumatin-like, URK1like, and WAK-like (Haffani et al. 2004). The most prevalent of the extracellular domains is the LRR domain followed by carbohydrate binding motifs (Lys-M, L-lectin, and C-type lectin; Herve et al. 1999). LRR-containing RLK represent the largest group of RLK in A. thaliana with 216 members. These have been divided into 13 subfamilies (LRR I to LRR XIII) classified on the basis of domain organization (Dievart and Clark 2004), copy number and arrangement of LRR in the extracellular motif (because LRR primary sequence is largely uninformative), and the number of intron or exons in RLK genes (Zhang et al. 2006). RLK also can be classified according to conserved residues in the kinase domain (Krupa et al. 2004). In most RLK, there is a conserved arginine (R) and an "invariant" catalytic aspartate (D) in the activation loop of subdomain VI. Some RLK lack the conserved arginine (non-RD kinases) whereas a few lack both conserved residues (RDminus kinases; Dardick and Ronald 2006) (Figs. 2 and 4). The activation loop usually serves as a kinase activator by enhancing phosphotransferase efficiency (Adams 2003). Loosely, RD kinases are involved in developmental regulation whereas nonRD kinases are implicated in innate immunity (Dardick and Ronald 2006). LePRK1 and LePRK2 are RLK involved in pollen pistil interaction in tomato and belong to the RD-minus class (Muschietti et al. 1998). Here, the RD residues are replaced by a glycine $(\mathrm{G})$ and asparagine $(\mathrm{N})$ residues (Fig. 4). These proteins were shown to possess kinase activity in vitro and LePRK2 also showed activity in mature pollen membranes (Muschietti et al. 1998). Similarly, the soybean (G. max) cyst nematode (SCN; Heterodera glycines) resistance-associated protein RHG1 (Afzal and Lightfoot 2007) also belonged to the RD-minus class. RD-minus proteins lacked the catalytic as well as the coordination residue; therefore, they presumably function by some other, as yet unknown, mechanism.

Phylogenetic analysis of the kinase domain from 13 diverse RLK yielded similar results, and three well-supported groups formed (Zhang et al. 2006). Viral defense genes clustered together whereas genes involved in brassinosteroid signaling and embryogenesis cluster within one subgroup, although some overlapping also was observed. On the basis of $\mathrm{dN} / \mathrm{dS}$ ratios, the authors concluded that the ligand-binding sites among one subgroup had been subjected to purifying selection which might elicit responses to similar ligands within this group. On the other hand, positive selection in the LRR has also led to sequence divergence between the three lineages. Hence, interlineage perception may employ different effectors or signals. Similarly, it was noted that the PAMP receptors FLS2 and ELR (elongation factor receptor) and $\mathrm{R}$ protein receptors XA21 and PTO fall into the same RLK subfamily, XII (Ryan et al. 2007). For our phylogenic analysis, we used A. thaliana RLK sequences with known functions spanning all 13 RLK subfamilies (Shiu and Bleecker 2001b supplementary information). Plant proteins involved in resistance formed a separate clade from most developmentally related RLK proteins. Interestingly, the dual function ERECTA and BRI1 formed an intermediary clade (Supplementary Fig. 1).

The domain architecture of RLK has been mostly conserved between rice and Arabidopsis RLK members, suggesting its establishment before the monocot-dicot split. (Shiu et al. 2004). Clustered kinases show similar extracellular domains, thereby indicating that the expansion of the RLK family occurred after fusion of the kinase domains to different extracellular domains (Haffani et al. 2004). Further, there are 43 different intron sites found in A. thaliana RLK kinase domains. Most members of the subfamily also contain conserved intron positions within the kinase domain. (Shiu and Bleecker 2001b).

\section{LRR structure.}

The LRR of the extracellular type is characterized by the consensus sequence LxxLxLxxNxLxx. There is little sequence similarity outside this consensus core (Braun and Walker 1996). A typical LRR belongs to the $3,6,12$, or 24 repeat subfamily of LRR and can be subdivided into six subfamilies (Kajava 1998). Protein structure solved for porcine ribonuclease inhibitor (RI) shows that the 15 LRR of RI are composed of an inner surface $\beta$ sheet rim connected to an outer rim of $\alpha$ helical segment (Kobe and Deisenhofer 1994). The $\alpha$ helical region forces a curvature on the molecule so that it forms a

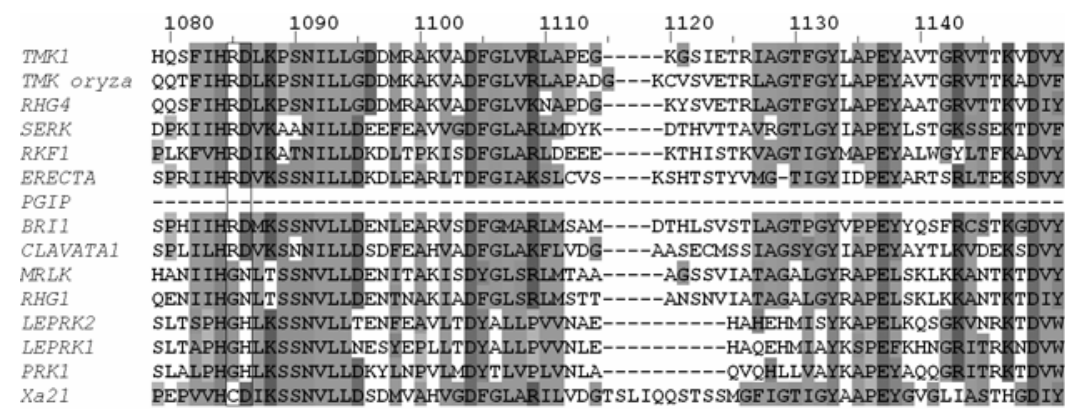

Fig. 4. Clustal W alignment of the kinase activation segment (segment VI) for known receptor-like kinases (RLKs). Kinases can be divided into three classes based on the presence or absence of the invariant $\mathrm{D}$ and conserved $\mathrm{R}$ residues (shown in box). Most of the RLKs shown belong to the RD kinase class. XA21 belongs to the non-RD class, whereas MRLK, LePRK1, LePRK2, PRK1, and RHG1 belong to the RD-minus class. Functional details in RD-minus kinases are not known. 
nearly full circle leaving a $60^{\circ}$ opening. It is through this opening of the solvent-exposed $\beta$ sheets that LRR may interact with the pathogen elicitor or presenting protein (Fluhr 2001). An 11-residue region in the LRR that corresponds to $\beta 1$ and adjacent loop is a characteristic feature of LRR. Interestingly, variation in this region leads to the six subfamilies mentioned earlier. The variant residues may lead to structural differences as well as binding specificities (Kajava and Kobe 2002).

The extracellular LRR and intracellular kinase domains are presumed to be under different selective constraints governed mainly by their roles (Braun and Walker 1996). The extracellular domain appears to experience diversifying selection pressure, possibly in order to recognize a multitude of extracellular signals, whereas the kinase domain appears to experience purifying selection pressure due to the functional and structural constraints involved in signal transduction (Supplementary Fig. 2). Motif-based alignment from 15 known LRR kinases shows conserved motif organization in the kinase domain but lack thereof in the extracellular LRR domain. Indeed, the $\beta$ sheet coding regions in LRR have been shown to be solvent-exposed hypervariable regions, having higher $\mathrm{Ka} / \mathrm{Ks}$ ratios (synonymous to nonsynonymous mutation ratio) (Zhang et al. 2006).

The first report of crystal structure of a plant LRR involved in defense was determined by Di-Matteo and associates (2003). Polygalacturonase-inhibiting proteins (PGIP) are plant cell wall proteins which confer resistance against phytopathogenic fungi. The protein falls into the plant-specific family of LRR (Kajava 1998). The structure of PGIP is a novel LRR structure containing two $\beta$ sheets in place of the characteristic one predicted by computer modeling and common in animal tyrosine kinases. The extra $\beta$ sheet or $\beta$ turn structure is characterized by a plant-specific Lt/sGxip motif instead of the LXXLP motif. This region is thought to provide an additional surface for interaction and is likely to be conserved in other plant LRR proteins as well (Afzal and Lightfoot 2007; DiMatteo et al. 2003). Some structural biologists are convinced that, due to the extra $\beta$ sheet, a majority of plant LRR would produce a $\beta$ helix structure similar to pectate lyase (Kajava and Kobe 2002); however, this remains to be established. A single amino acid change in the $\beta$ region of PGIP1 and PGIP2 has been shown to change recognition specificity. Only one of the eight varying residues in both RLK can account for this observed change. The other seven positively substituted amino acid changes may have roles in recognition of other PG ligands. Similarly, in the Cf family of RLK, most variant residues between family members CF9 and CF4 are not essential for specificity. Here, too, the CF $\beta$ solvent-exposed domain does not seem to be designed to interact with only one ligand (Federici et al. 2006; van der Hoorn et al. 2005). However, most of the 22 sites of $\mathrm{N}$-glycosylation on the outer helices are essential to function. Equally, the conserved Trp Cys pairs on the concave inner surface are essential to function and, on this surface, $\mathrm{N}$ glycosylation interferes with function. Here, too, the $\beta$-helical hydrophobic and $\alpha$-helical solvent-exposed domains do not seem to be designed to interact with only one ligand.

Also in this class are the LRR domains of plant RHG1 and RHG4 proteins that were associated with bigeneic resistance to SCN (Afzal 2007; Afzal and Lightfoot 2007; Ruben et al. 2006; A. J. Afzal, P. Kohli, and D. A. Lightfoot, unpublished). The methods developed to allow expression of the LRR domain in Escherichia coli have been used to identify interacting partner. The solubilization methods and the availability of ligand libraries may allow a rapid determination of the functions of the LRR domains of many RLK proteins.

It is not known whether the kinase class will impact predictions of the binding partners of the LRR domains. However, factors that bind the cytoplasmic face of Cf9 activate a trans- duction pathway without enzyme activity, suggesting that structural changes are occurring (Nekrasov et al. 2006). Further, kinase domains with a strong tendency to dimerize were expected to alter the structure of the LRR domains as force is transduced through the membrane. In an extreme case, dimerization among the LRR domains and among the kinase-associated domains might be competitive (Barker et al. 2006).

\section{How plants cope with pathogens.}

The focus on a gene-for-gene relationships, which render a given plant cultivar carrying a specific resistance gene resistant to a given biotype of the pathogen bearing a corresponding avirulence gene, has been a common oversimplification (Gomez-Gomez and Boller 2002). That specific recognition system is somewhat similar to the part of the response of the adaptive immune system in animals where antigen-specific antibodies are generated to combat the pathogen producing the antigen. Acquired immunity in animals, having arisen by clonal expansion, offers the benefit of complete non-self coverage $\left(10^{7}\right.$ different gene products/Mbp coding sequence). In contrast, plant innate immunity is more costly in its information content (approximately $2 \times 10^{2}$ different gene products/Mbp coding sequence). Moreover, the plant gene-for-gene interaction system is genetically fixed, unlike the animal system, which has somatic combinatorial flexibility (Gomez-Gomez and Boller 2002). Nevertheless, plants lacking combinatorial flexibility employ some strategies that also are observed in animal systems.

First, plants, like animals, have the capacity to detect pathogens in a broad combinatorial way by detecting several general elicitors (Ebel and Mithofer 1998). These elicitor molecules are kingdom specific rather than pathotype or species specific. Examples such as flagellin, chitin, pilin, and ergosterol are noteworthy (Fig. 1) (Granado et al. 1995). The plant's response to general elicitors includes the production of ROS and ethylene and activation of the partial defense response genes (Boller 1995). In some cases, a single resistance $(R)$ gene specific for one pathogen also can serve to recognize other, or even multiple, general elicitors. For instance, the tomato $\mathrm{Mi}$ gene that confers specific resistance to nematodes and aphids also provides some protection from herbivorous insects (Grant et al. 1995; Nombela et al. 2003; Rossi et al. 1998). Equally, the RHG4 protein associated with $\mathrm{SCN}$ resistance may provide some protection from herbivorous insects (C. R. Yesudas and D. A. Lightfoot, unpublished) and RHG1 protein provides some resistance to Fusarium virguliforme (Ruben et al. 2006; Triwitayakorn et al. 2005).

Greatly amplifying $R$ gene numbers combined with rapid rates of $R$ gene extracellular domain evolution seem to be the two ways in which plants combat a wide array of pathogens (Fluhr 2001). On the basis of comparative mapping of $R$ gene analogs in monocots, it can be demonstrated that $R$ genes diverge more rapidly than the rest of the genome, through sequence divergence or recombination (Leister et al. 1998). In some cases, such as the barley powdery mildew gene mlo or stem rust resistance gene Rpgl, no genes were found in the syntenic regions in rice. Similarly, at $r h g 1$, the G. $\max \mathrm{SCN}$ resistance gene (Ruben et al. 2006; Triwitayakorn et al. 2005) the RLK was absent from the corresponding Medicago truncatula syntenic gene cluster (Mudge et al. 2005). These observations are indicative of the rapid global rate of $R$ gene evolution (Brueggeman et al. 2002).

$R$ genes belonging to different structural classes conferring resistance to a different set of pathogens were present in nonoverlapping discrete clusters in the plant genome (Farrara et al. 1987; Parniske et al. 1997). Within a discrete cluster, members of a family are arranged mostly as tandem repeats indicative of their origin through gene duplication events (Ronald 1998). 
For example, the presence of two almost identical tomato $C f-2$ genes suggests that they arose through a recent gene duplication event (Dixon et al. 1996). Phaseolus vulgaris PGIP are members of a four-gene family having arisen through duplication. The PGIP encode proteins that differ by 8 to 81 amino acids. Perhaps Phaseolus spp. have evolved many PGIP with different specificities against the many PGs secreted by the pathogen (Di-Matteo et al. 2003). This also has been seen in the case of the $X a 21$ multigene family for resistance to rice blast. Here, a 17-kb segment has been shown to be duplicated that confers the same race specific resistance as XA-21. Closely identical paralogs of the RLK at both $r h g 1$ and Rhg 4 are found within duplicated syntenic blocks at three regions of the genome and may function in SCN resistance (A. J. Afzal and D. A. Lightfoot, unpublished; Campbell et al. in press). Duplicated genes can relieve structural and functional constraints associated with signal gene to receptor gene recognition systems. Simply stated, the extra, duplicated, gene or genes can evolve without disrupting the protection associated with the progenitor gene for gene recognition.

DNA rearrangements play a significant role in plant resistant gene evolution (Pryor and Ellis 1993). For the maize rpl gene locus, reassortment events such as recombination and gene conversion of $r p l$ flanking markers are linked with the creation of novel resistance phenotypes (Richter et al. 1995). In addition to swapping large gene regions, recombination can lead to fine structural changes. For the Flax $M$ rust gene, mutants of the $M$ gene were found that contained a single repeat that codes for the LRR region rather than the usual two repeats found in the wild-type gene (Anderson et al. 1997). In the case of SRK, alternate splicing leads to recognition flexibility. Here, a full-length receptor kinase and a secreted product found in the ectoderm were detected in Brassica oleracea (Giranton et al. 2000). Both plants and animals may control antigen recognition at multiple layers, with the two or more RLK gene products having different specificities for the elicitors. Finally, alternate splicing also has been observed in the $N$ resistance gene in tomato, where the presence of both the $N$ gene products $N_{\mathrm{S}}$ and $N_{\mathrm{L}}$ is essential for Tomato mosaic virus resistance (Kumar and Baker 2000).

Transposon-like elements (TE) have long been known to play a role in genome reconstruction in response to environmental stresses such as pathogen invasion (Wessler et al. 1995). TE-induced gene alteration is shown to cause gene activation in the case of the maize fungal resistance gene $\mathrm{Hml}$. However, by 2008, there was no evidence for the generation of new $R$ gene specificities due to insertion or excision of TE, although it is tempting to speculate that transposons contribute positively to evolution of $R$ gene diversity (Ronald 1998).

Multiple opportunities for variation appear to be the most common function of the LRR domains (Bergelson et al. 2001). Somatic variation among RLK may be inferred from the high mutation rates observed that phenomenon has not yet been reported. Resistance to fixation after crosses has been found to encompass the RLK allotypes at rhgl (Meksem et al. 1999, 2001; Triwitayakorn et al. 2005) and nucleotide-binding site LRR alleles at Rps4 (Sandhu et al. 2004). Evidence for meiotic drive derives from very unusual segregation ratios of markers and phenotypes at rhgl (Bell-Johnson et al. 1998; Prabhu et al. 1999; Webb et al. 1995). The resistance allele at $r h g l$ requires a modifier allele at an unlinked locus. It has been hypothesized that this other factor may interact with the RLK.

\section{Some pathogen defense strategies are common between plants and animals.}

Innate immunity in animals is related to the recognition of PAMPs such as fungal mannans, bacterial polysaccharides, and flagellin (Medzhitov and Janeway 2000). In both plants and animals, bacterial flagellin protein (FLG22) is recognized by cell surface receptors (FLS2 in Arabidopsis and TLR5 in mammals); hence, the concept of innate immunity also has emerged with the identification of pattern recognition receptors involved in PAMP recognition (Nürnberger and Kemmerling 2006). Both receptors are membrane localized and contain extracellular LRR (Fig. 1). Another similarity is that plants, like animal LRR receptors, are believed to transduce most signals through the activation of co-receptors or accessory proteins (Dievart and Clark 2004). For instance, in rice, XA21 protein requires XB3 for complete $\mathrm{Xa}$-21-mediated disease resistance (Wang et al. 2006; Fig. 3A). Although the extracellular domains in plant RLK differ structurally from most animal receptors (Dunne and O'Neill 2003), there are some parallels. Mammalian Toll-like receptors (TLR) and Drosophila melanogaster Toll receptors have extracellular LRR domains that resemble plant RLK LRR. The LRR in both animals and plants has been used as an interaction motif (Dievart and Clark 2004). Unlike plant RLK, most of the extracellular RLK domains found in animal genomes have no association with kinase domains. Therefore, the domain composition in RLK/Pelle family members may have been established during the course of plant evolution (Shiu et al. 2004; Zapata et al. 2000). Interestingly, in D. melanogaster, the activation of Toll recruits a complex containing at least three proteins. One of the proteins recruited by Toll is a cytoplasmic ser/thr kinase which has high homology to the cytoplasmic ser/thr kinase domain of LRR containing RLK (Dievart and Clark 2004). Recognition results in the formation of ROS, changes in ion flux, and rapid phosphorylation of the kinase domains. Furthermore, both invoke the activation of the mitogen-activated protein kinase (MAPK) cascade and activation of defense-related genes (Gomez-Gomez and Boller 2002). The transduction of signal, after recognitions of PAMPs by the Toll receptor, proceeds by interlukin-1 receptor-associated kinases, which are homologs of the fruit fly Pelle genes (Cao et al. 1996). Equally, the hypersensitive-response-based gene-for-gene relationship in plants as seen in the case of rice $X a-21$ is reminiscent of adaptive immunity in animals. The hypersensitive response programmed cell death is similar to innate immunity programmed cell death because both require active transcription and translation and are genetically determined (Lam et al. 2001) (Fig. 1). Last, animal PELLE proteins contribute toward the establishment of dorsal or ventral patterning as well as innate immunity (Shiu and Bleecker 2001a) similar to the plant ERECTA RLK. Similarly, the human LRR DECRIN binds a diverse array of ligands (Scott et al. 2004) similar to BRI1 in plants (Morris and Walker 2003; Szekerses 2003). In summary, it is clear that plants and animals both employ LRR-containing receptors for pathogen detection, STK to relay signals, and MAPK for downstream defense response.

\section{Models for plant RLK function.}

Current understanding of receptor kinase function holds that the plant RLK perceive signals through their extracellular domain and propagate the signal through the intracellular kinase domain (Shiu and Bleecker 2001a). In some known instances, RLK exist in membranes as inactive monomers (Becraft 1998; Nam and Li 2002). Ligand binding induces a conformation change in the extracellular domain which is hypothesized to result in dimerization, thereby bringing the intracellular kinase domains into close proximity (Fig. 3B). That domain proximity is hypothesized to lead to transphosphorylation. The kinase domain of RLK5 from A. thaliana transphosphorylates, suggesting that oligomerization plays a 
role in protein activation (Horn and Walker 1994). Overexpression of the Arabidopsis SERK causes dimer formation that leads to embryonic competence (Hecht et al. 2001; Shah et al. 2001a). However, transient studies have shown that only a small portion of the SERK1 receptors exist as dimers, suggesting that SERK1, too, may undergo ligand-dependent dimerization (Shah et al. 2001a). CLV1 and SRK proteins have been shown to function with co-receptors which lack the kinase domain, suggesting that this might be a common feature to RLK signaling (Becraft 2002). There are exceptions to that general model. For instance, some plant receptor kinases exist as multimers in their inactive form (Giranton et al. 2000), such as the S-locus receptor kinase of Brassica spp. (Goring and Rothstein 1992). CrRLK1 from Catharanthus rosea shows autophosporlyation, suggesting that oligomerization is not required for CrRLK activation (Fig. 3C) (Schulze-Muth et al. 1996). As a general rule, RLK with known extracellular domains transphosphorylate whereas kinases with no known extracellular receptor (e.g., Pto) (Fig. 3D) or RLK containing unique extracytoplasmic receptor domains often autophosphorylate. However, the actual mode of action for each RLK on the basis of structural identity cannot be assumed and must be determined experimentally. Some disease-resistant proteins, such as XA-21 from rice, require an accessory protein to impart stability to the $\mathrm{R}$ protein. Upon pathogen infection, the accessory protein, XB3, a ubiquitin ligase, is phosphorylated by XA-21, which serves as a defense signal (Fig. 3A; Wang et al. 2006). Only in a few cases has direct interaction between the Avr protein and the $\mathrm{R}$ protein been shown experimentally. For instance, for the rice protein Pita, direct physical interaction with the corresponding AvrPita protein has been established (Jia et al. 2000). The lack of substantial evidence for direct Avr-R interaction led to the "guard hypothesis" (Van der Biezen and Jones 1998). The guard hypothesis proposed that the R protein "guards" key virulence targets inside the cell. Upon infection, the Avr protein modifies these virulence targets or "guardee" molecules. Perception of the altered guardee status signals the $\mathrm{R}$ protein to induce the defense response (Fig. $3 \mathrm{G})$. The guard hypothesis is gaining support based on recent work on NBS-LRR proteins (Coaker et al. 2005), suggesting that indirect recognition may be a common feature in plant innate immunity.

\section{Conclusion.}

RLK in plants function as a central processing unit, accepting parallel input signals either internally (from the plant itself) or externally and converting them into appropriate output signals that lead to changes in metabolism, gene expression, or development (Hardie 1999). Perception of PAMPs in animal immunity corresponds to recognition of general elicitors in plants (Gomez-Gomez and Boller 2002). Like animals, plants use many intricate and complex pathways to recognize signals. Receptors are simply a starting point of what is eventually a very complex set of signal pathways, where there is cross talk between pathways, feedback looping, and convergence of multicomplex units to enable transcription of target genes. Deciphering RLK function is complicated in plants due to the functional redundancy between receptors. Arabidopsis alone has 216 LRR RLK, but only a very few have been associated with biological functions. Even when the function is known, the sequence of events from recognition to response is, at the most, sketchy. In the coming years, researchers need to explore the effect of protein structure on both upstream (ligands and their presenting partners) and downstream (effectors and their ramifying networks) targets to develop a more comprehensive picture of plant signal transduction pathways.

\section{LITERATURE CITED}

Adams, J. A. 2003. Activation loop phosphorylation and catalysis in protein kinases: Is there functional evidence for the auto inhibitor model? Biochemistry 42:601-607.

Afzal. J. A 2007. Structure-function analysis of a candidate receptor like kinase protein in soybean cyst nematode resistance and identification of accessory proteins involved in plant defense. Ph.D. dissertation, Department of Molecular Biology, Microbiology and Biochemistry, Southern Illinois University, Carbondale, U.S.A.

Afzal, J. A., and Lightfoot, D. A. 2007. Expression of the LRR domain of RHG1 in E. coli: Preparation for functional analyses. Protein Expr. Purif. 53:346-355.

Anderson, P. A., Lawrence, G. J., Morrish, B. C., Ayliffe, M. A., Finnegan, E. J., and Ellis, J. G. 1997. Inactivation of the flax rust resistance gene $M$ associated with loss of a repeated unit within the leucine-rich repeat coding region. Plant Cell 4:641-651.

Baker, B., Zambryski, P., Staskawicz, B., and Kumar, D. S. P. 1997. Signaling in plant-microbe interactions. Science 276:726-733.

Barker C. L., Baillie B. K., Hammond-Kosack K. E., Jones J. D. G., and Jones, D. A. 2006. Dominant-negative interference with defence signalling by truncation mutations of the tomato $\mathrm{Cf}-9$ disease resistance gene. Plant J. 46:385-399.

Becraft, P. W. 1998. Receptor kinases in plant development. Trends Plant Sci. 3:384-488.

Becraft, P. W. 2002. Receptor kinase signaling in plant development. Annu. Rev. Cell Dev. Biol. 18:163-192.

Bell-Johnson, B. B., Garvey, G., Johnson, J., Meksem, K., and Lightfoot, D. A. 1998. Methods for high-throughput marker assisted selection for soybean. Soybean Genet. Newsl. 25:115-118.

Bergelson, J., Kreitman, M., Stahl, E. A., and Tian, D. 2001. Evolutionary dynamics of plant R-genes. Science 292:2281-2285.

Bleecker, A. B., and Kende, H. 2000. Ethylene: A gaseous signal molecule in plants. Annu. Rev. Cell Dev. Biol. 16:1-18.

Bogdanove, A. J., and Martin, G. B. 2000. AvrPto-dependent Pto-interacting proteins and AvrPto-interacting proteins in tomato. Proc. Natl. Acad. Sci. U.S.A. 97:8836-8840.

Bögre, L., Ökrész, L., Henriques, R., and Anthony R.G. 2003. Growth signalling pathways in Arabidopsis and AGC protein kinases. Trends Plant Sci. 8:424-431.

Boller, T. 1995. Chemoperception of microbial signals in plant cells. Annu. Rev. Plant Physiol. Plant Mol. Biol. 46:189-214.

Braun, D. M., and Walker, J. C. 1996. Plant transmembrane receptors: New pieces in the signaling puzzle. Trends Biochem. Sci. 21:70-73.

Brueggeman, R., Rostoks, N., Kudrna, D., Kilian, A., Han, F., Chen, J., Druka, A., Steffenson, B., and Kleinhofs, A. 2002. The barley stem rust-resistance gene Rpgl is a novel disease-resistance gene with homology to receptor kinases. Proc. Natl. Acad. Sci. U.S.A. 99:9328 9333.

Campbell, N., Matthews, B. F., Lightfoot, D. A., and Knap, H. Identification of duplicated regions that encompass paralogs of Rhg4. Mol. Breed. In press.

Cao, Z., Henzel, W. J., and Gao, X. 1996. IRAK: A kinase associated with the interleukin-1 receptor. Science 271:1128-1131.

Chinchilla, D., Bauer, Z., Regenass, M., Boller, T., and Felix, G. 2006. The Arabidopsis receptor kinase FLS2 binds flg22 and determines the specificity of flagellin perception. Plant Cell 18:465-476.

Chinchilla, D., Zipfel, C., Robatzek, S., Kemmerling, B., Nürnberger, T., Jones, J. D., Felix, G., and Boller, T. 2007. A flagellin-induced complex of the receptor FLS2 and BAK1 initiates plant defence. Nature 448:497-500.

Clark, S. E., Williams, R. W., and Meyerowitz, E. M. 1997. The CLAVATA1 gene encodes a putative receptor kinase that controls shoot and floral meristem size in Arabidopsis. Cell 89:575-585.

Coaker, G., Falick, A, and Staskawicz, B. 2005. Activation of a phytopathogenic bacterial effector protein by a eukaryotic cyclophilin. Science 308:548-550.

Dardick C, and Ronald P. 2006. Plant and animal pathogen recognition receptors signal through non-RD kinases. PLoS Pathog. 2:1-15.

DeYoung, B. J., and Innes, R. W. 2006. Plant NBS-LRR proteins in pathogen sensing and host defense. Nat. Immunol. 7:1243-1249.

Dievart, A., and Clark, S. E. 2004. LRR-containing receptors regulating plant development and defense. Development 131:251-261.

Di-Matteo, A., Federici, L., Mattei, B., Salvi, G., Johnson, K. A., Savino, C., DeLorenzo, G., Tsernoglou, D., and Cervone, F. 2003. The crystal structure of polygalacturonase-inhibiting protein PGIP., a leucine-rich repeat protein involved in plant defense. Proc. Natl. Acad. Sci. U.S.A. 100:10124-10128.

Dixon, M. S., Jones, D. A., Keddie, J. S., Thomas, C. M., Harrison, K., and Jones, J. D. 1996. The tomato $C f$-2 disease resistance locus com- 
prises two functional genes encoding leucine-rich repeat proteins. Cell $84: 451-459$

Doebley, J., and Lukens, L. 1998. Transcriptional regulators and the evolution of plant form. Plant Cell 10:1075-1082.

Dunne, A., and O'Neill, L. A. 2003. The interleukin-1 receptor/Toll-like receptor superfamily: Signal transduction during inflammation and host defense. Sci. STKE 171:re3.

Ebel, J., and Mithofer, A. 1998. Early events in the elicitation of plant defence. Planta 206:335-348.

Eckardt, N. A. 2005. Brassinosteroid perception and signaling: Heterodimerization and phosphorylation of receptor-like kinases BRI1 and BAK1. Plant Cell. 17:1638-1640.

Farrara, B. F., Ilott, T. W., and Michelmore, R. W. 1987. Genetic analysis of factors for resistance to downy mildew Bremia lactucae in species of lettuce Lactuca sativa and L. serriola. Plant Pathol. 36:499-514.

Federici, L., Di Matteo, A., Fernandez-Recio, J., Tsernoglou, D., and Cervone, F. 2006. Polygalacturonase inhibiting proteins: Players in plant innate immunity? Trends Plant Sci. 11:65-70.

Fluhr, R. 2001. Sentinels of disease: Plant resistance genes. Plant Physiol 127:1367-1374.

Gachomo, E. W., Shonukan, O. O., and Kotchoni, S. O. 2003. The molecular initiation and subsequent acquisition of disease resistance in plants. Afr. J. Biotechnol. 2:26-32.

Giranton, J. L., Dumas, C., Cock, J. M., and Gaude, T. 2000. The integral membrane S-locus receptor kinase of Brassica has serine/threonine kinase activity in a membranous environment and spontaneously forms oligomers in planta. Proc. Natl. Acad. Sci. U.S.A. 97:3759-3764.

Godiard, L., Sauviac, L., Torii, K. U., Grenon, O., Mangin, B., Grimsley, N. H., and Marco, Y. 2003. ERECTA, an LRR receptor-like kinase protein controlling development pleiotropically affects resistance to bacterial wilt. Plant J. 36:353-365.

Gomez-Gomez, L., and Boller, T. 2000. FLS2: An LRR receptor-like kinase involved in the perception of the bacterial elicitor flagellin in Arabidopsis. Mol. Cell 5:1003-1011.

Gomez-Gomez, L., and Boller, T. 2002. Flagellin perception: A paradigm for innate immunity. Trends Plant Sci. 7:251-256.

Goring, D. R., and Rothstein, S. J. 1992. The S-locus receptor kinase gene in a self-incompatible Brassica napus line encodes a functional serine/ threonine kinase. Plant Cell 4:1273-1281.

Goring, D. R., and Walker, J. C. 2004. Plant sciences. Self-rejection, a new kinase connection. Science 303:1474-1475.

Granado, J., Felix, G., and Boller, T. 1995. Perception of fungal sterols in plants: Sub-nanomolar concentrations of ergosterol elicit extra-cellular alkalinization in tomato cells. Plant Physiol. 107:485-490.

Grant, M. R., Godiard, L., Straube, E., Ashfield, T., Lewald, J., Sattler, A., Innes, R. W., and Dangl, J. L. 1995. Structure of the Arabidopsis RPMI gene enabling dual specificity disease resistance. Science 269:843-846.

Haffani, Y. Z., Silva, N. F., and Goring, D. R. 2004. Receptor kinase signalling in plants. Can. J. Bot. 82:1-15.

Hardie, D. G. 1999. Plant protein serine/threonine kinases: Classification and function. Annu. Rev. Plant Physiol. Plant Mol. Biol. 50:97-131.

Hecht, V., Vielle-Calzada, J. P., Hartog, M. V., Schmidt, E. D., Boutilier, K., Grossniklaus, U., and de Vries, S. C. 2001. The Arabidopsis SOMATIC EMBRYOGENESIS RECEPTOR KINASE 1 gene is expressed in developing ovules and embryos and enhances embryogenic competence in culture. Plant Physiol. 127:803-816.

Herve, C., Serres, J., Dabos, P., Canut, H., Barre, A., Rouge, P., and Lescure, B. 1999. Characterization of the Arabidopsis lecRK-a genes: Members of a super-family encoding putative receptors with an extra-cellular domain homologous to legume lectins. Plant Mol. Biol. 4:671-682.

Higuchi, M., Pischke, M. S., Mahonen, A. P., Miyawaki, K., Hashimoto, Y., Seki, M., Kobayashi, M., Shinozaki, K., Kato, T., Tabata, S., Helariutta, Y., Sussman, M. R., and Kakimoto, T. 2004. In planta functions of the Arabidopsis cytokinin receptor family. Proc. Natl. Acad. Sci. U.S.A. 101:8821-8826.

Horn, M. A., and Walker, J. C. 1994. Biochemical properties of the autophosphorylation of RLK5, a receptor-like protein kinase from Arabidopsis thaliana. Biochim. Biophys. Acta. 1208:65-74.

Ingram, C. G., and Waites, R. 2006. Keeping it together: Co-ordinating plant growth. Curr. Opin. Plant Biol. 9:12-20.

Inoue, T., Higuchi, M., Hashimoto, Y., Seki, M., Kobayashi, M., Kato, T., Tabata, S., Shinozaki, K., and Kakimoto, T. 2001. Identification of CRE1 as a cytokinin receptor from Arabidopsis. Nature 409:1060-1063.

Jeong, S., Trotochaud, A. E., and Clark, S. E. 1999. The Arabidopsis CLAVATA2 gene encodes a receptor-like protein required for the stability of the CLAVATA1 receptor-like kinase. Plant Cell 10:1925-1934.

Jia, Y., McAdams, S. A., Bryan, G. T., Hershey, H. P., and Valent, B. 2000. Direct interaction of resistance gene and avirulence gene products confers rice blast resistance. EMBO (Eur. Mol. Biol. Organ.) J. 19:40044014.
Jinn, T. L., Stone, J. M., and Walker, J. C. 2000. HAESA, an Arabidopsis leucine-rich repeat receptor kinase, controls floral organ abscission. Genes Dev. 14:108-117.

Kachroo, A., Schopfer, C. R., Nasrallah, M. E., and Nasrallah, J. B. 2001 Allele-specific receptor-ligand interactions in Brassica self-incompatibility. Science 293:1824-1886.

Kajava, A. V. 1998. Structural diversity of leucine-rich repeat proteins. J. Mol. Biol. 277:519-527.

Kajava, A.,V., and Kobe, B. 2002. Assessment of the ability to model proteins with leucine-rich repeats in light of the latest structural information. Protein Sci. 11:1082-1090.

Kobe, B., and Deisenhofer, J. 1994. The leucine-rich repeat: A versatile binding motif. Trends Biochem. Sci. 19:415-421.

Krupa, A., Preethi, G., and Srinivasan, N. 2004. Structural modes of stabilization of permissive phosphorylation sites in protein kinases: Distinct strategies in Ser/Thr and Tyr kinases. J. Mol. Biol. 339:1025-1039.

Krusell, L., Madsen, L. H., Sato, S., Aubert, G., Genua, A., Szczyglowski, K., Duc, G., Kaneko, T., Tabata, S., de Bruijn, F., Pajuelo, E., Sandal, N., and Stougaard, J. 2002. Shoot control of root development and nodulation is mediated by a receptor-like kinase. Nature 420:422-426.

Kumar, D. S. P., and Baker, B. J. 2000. Alternatively spliced $N$ resistance gene transcripts: Their possible role in Tobacco mosaic virus resistance. Proc. Natl. Acad. Sci. U.S.A. 97:1908-1913.

Lam, E., Kato, N., and Lawton, M. 2001. Programmed cell death, mitochondria and the plant hypersensitive response. Nature 411:848-853.

Leister, D., Kurth, J., Laurie, D.A., Yano, M., Sasaki, T., Devos, K., Graner, A., and Schulze-Lefert, P. 1998. Rapid reorganization of resistance gene homologues in cereal genomes. Proc. Natl. Acad. Sci. U.S.A. 95:370375 .

Li, J., and Chory, J. 1997. A putative leucine-rich repeat receptor kinase involved in brassinosteroid signal transduction. Cell 90:929-938.

Li, J., Wen, J., Lease, K. A., Doke, J. T., Tax, F. E., and Walker, J. C. 2002. $B A K 1$, an Arabidopsis LRR receptor-like protein kinase, interacts with BRI1 and modulates brassinosteroid signaling. Cell 110:213-222.

Medzhitov, R., and Janeway, C. Jr. 2000. Innate immune recognition: Mechanisms and pathways. Immunol. Rev. 173:89-97.

Meksem, K., Doubler, T. W., Chancharoenchai, K., Njiti, V., Chang, S. J. C., Rao Arelli, A. P., Cregan, P. E., Gray, L. E., Gibson, P. T., and Lightfoot, D. A. 1999. Clustering among loci underlying soybean resistance to Fusarium solani, SDS and SCN in near-isogenic lines. Theor Appl. Genet. 99:1131-1142.

Meksem, K., Pantazopoulos, P., Njiti, V. N., Hyten, L. D., Arelli, P. R., and Lightfoot, D. A. 2001. 'Forrest' resistance to the soybean cyst nematode is bigenic: Saturation mapping of the rhgl and Rhg4 loci. Theor. Appl. Genet. 103:710-717.

Morillo, S. A., and Tax, F. E. 2006. Functional analysis of receptor-like kinases in monocots and dicots. Curr. Opin. Plant Biol. 9:460-469.

Morris, E. R., and Walker, J. C. 2003. Receptor-like protein kinases: The keys to response. Curr. Opin. Plant Biol. 6:339-342.

Mu, J. H., Lee, H. S., and Kao, T. H. 1994. Characterization of a pollenexpressed receptor-like kinase gene of Petunia inflata and the activity of its encoded kinase. Plant Cell 6:709-721.

Mudge, J., Cannon, S. B., Kalo, P., Oldroyd, G. E., Roe, B. A., Town, C. D., and Young, N. D. 2005. Highly syntenic regions in the genomes of soybean, Medicago truncatula, and Arabidopsis thaliana. BMC Plant Biol. 5:15-25.

Muschietti, J., Eyal, Y., and McCormick, S. 1998. Pollen tube localization implies a role in pollen-pistil interactions for the tomato receptor-like protein kinases LePRK1 and LePRK2. Plant Cell 103:319-330.

Nadeau, J. A., and Sack, F. D. 2002. Control of stomatal distribution on the Arabidopsis leaf surface. Science 296:1697-1700.

Nam, K. H., and Li, J. 2002. BRI1/BAK1, a receptor kinase pair mediating brassinosteroid signaling. Cell 26:203-212.

Nekrasov V., Ludwig A. A., and Jones J. D. 2006. CITRX thioredoxin is a putative adaptor protein connecting $\mathrm{Cf}-9$ and the ACIK1 protein kinase during the Cf-9/Avr9- induced defence response. FEBS (Fed. Eur. Biochem. Soc.) Lett. 580:4236-4241.

Nombela, G., Williamson, V. M., and Muniz, M. 2003. The root-knot nematode resistance gene $\mathrm{Mi}-1.2$ of tomato is responsible for resistance against the whitefly Bemisia tabaci. Mol. Plant-Microbe Interact. 16:645-649.

Nürnberger, T., and Kemmerling, B. 2006. Receptor protein kinases-Pattern recognition receptors in plant immunity Trends Plant Sci. 11:519522.

Parniske, M., Hammond-Kosack, K. E., Golstein, C., Thomas, C. M., Jones, D. A., Harrison, K., Wulff, B. B., and Jones, J. D. 1997. Novel disease resistance specificities result from sequence exchange between tandemly repeated genes at the Cf-4/9 locus of tomato. Cell 91:821832.

Prabhu, R. R., Njiti, V., Johnson, J. E., Schmidt, M. E., Klein, R. J., and 
Lightfoot, D. A. 1999. Selecting soybean cultivars for dual resistance to cyst nematode sudden death syndrome with two DNA markers. Crop Sci. 39:982-987.

Pillitteri, L. J., Bemis, S. M., Shpak, E. D., and Torii, K. U. 2007. Haploinsufficiency after successive loss of signaling reveals a role for ERECTA-family genes in Arabidopsis ovule development. Development 17:3099-3109.

Pryor, A. J., and Ellis, J. 1993. The genetic complexity of fungal disease resistance genes in plants. Adv. Plant Pathol. 10:281-305.

Richter, T. E., Pryor, T. J., Bennetzen, J. L., and Hulbert, S. H. 1995. New rust resistance specificities associated with recombination in the $R p I$ complex in maize. Genetics 141:373-381.

Ronald, P. C. 1998. Resistance gene evolution. Curr. Opin. Plant Biol. 1:294-298.

Rossi, M., Goggin, F. L., Milligan, S. B., Kaloshian, I., Ullman, D. E., and Williamson, V. M. 1998. The nematode resistance gene $\mathrm{Mi}$ of tomato confers resistance against the potato aphid. Proc. Natl. Acad. Sci. U.S.A. 95:9750-9754.

Ruben, E., Jamai, A., Afzal, J., Njiti, V. N., Triwitayakorn, T., Iqbal, M. J., Yaegashi, S., Bashir, R., Kazi, S., Arelli, P., Town, C. D., Ishihara, H., Meksem, K., and Lightfoot, D. A. 2006. Genomic analysis of the rhg1 locus: Candidate genes that underlie soybean resistance to the cyst nematode. Mol. Genet. Genomics 276:503-516.

Ryan, C. A., Huffaker, A., and Yamaguchi, Y. 2007. New insights into innate immunity in Arabidopsis. Cell Microbiol. 9:1902-1908.

Sandhu, D., Gao, H., Cianzio, S., and Bhattacharyya, M. K. 2004. Deletion of a disease resistance nucleotide-binding-site leucine-rich-repeatlike sequence is associated with the loss of the Phytophthora resistance gene Rps4 in soybean. Genetics 168:2157-2167.

Schulze-Muth, P., Irmler, S., Schroder, G., and Schroder, J. 1996. Novel type of receptor-like protein kinase from a higher plant Catharanthus roseus cDNA, gene, intramolecular autophosphorylation, and identification of a threonine important for auto- and substrate phosphorylation. J. Biol. Chem. 271:26684-26689.

Scott, P. G., McEwan, P. A., Dodd, C. M., Bergmann, E. M., Bishop, P. N., and Bella, J. 2004. Crystal structure of the dimeric protein core of decorin, the archetypal small leucine-rich repeat proteoglycan. Proc. Natl. Acad. Sci. U.S.A. 101:15633-15638.

Shah, K., Gadella, T. W., Jr., van Erp, H., Hecht, V., and de Vries, S. C. 2001a. Cellular localization and oligomerization of the Arabidopsis thaliana somatic embryogenesis receptor kinase 1 protein. J. Biol. Chem. 309:641-655.

Shah, K., Vervoort, J., and de Vries, S. C. 2001b. Role of threonines in the Arabidopsis thaliana somatic embryogenesis receptor kinase 1 activation loop in phosphorylation. J. Biol. Chem. 276:41263-41269.

Sharma, V. K., Ramirez, J., and Fletcher, J. C. 2003. The Arabidopsis $C L V 3$-like $C L E$. genes are expressed in diverse tissues and encode secreted proteins. Plant Mol. Biol. 3:415-425.

Shi, P., Zhang, J., Yang, H., and Zhang, Y. P. 2003. Adaptive diversification of bitter taste receptor genes in Mammalian evolution. Mol. Biol. Evol. 20:805-814

Shiu, S. H., and Bleecker, A. B. 2001a. Plant receptor-like kinase genefamily: Diversity, function, and signaling. Sci. Sig. Trans. Knowl. Environ. 113:re22.

Shiu, S. H., and Bleecker, A. B. 2001b. Receptor-like kinases from Arabidopsis form a monophyletic gene-family related to animal receptor kinases. Proc. Natl. Acad. Sci. U.S.A. 98:10763-10768.

Shiu, S. H., and Bleecker, A. B. 2003. Expansion of the receptor-like kinase/Pelle gene-family and receptor-like proteins in Arabidopsis. Plant Physiol. 132:530-543.

Shiu, S. H., and Li, W. H. 2004. Origins, lineage-specific expansions, and multiple losses of tyrosine kinases in eukaryotes. Mol. Biol. Evol. 21:828-840

Shiu, S. H., Karlowski, W. M., Pan, R., Tzeng, Y. H., Mayer, K. F., and Li,
W. H. 2004. Comparative analysis of the receptor-like kinase family in Arabidopsis and rice. Plant Cell 16:1220-1234.

Song, W. Y., Wang, G. L., Chen, L. L., Kim, H. S., Pi, L. Y., Holsten, T., Gardner, J., Wang, B., Zhai, W. X., and Zhu, L. H. 1995. A receptor kinase-like protein encoded by the rice disease resistance gene, Xa21. Science 270:1804-1806.

Szekeres, M. 2003. Brassinosteroid and systemin: Two hormones perceived by the same receptor. Trends Plant Sci. 8:102-104.

Tierens, K. F. M-J., Thomma, B. P. H. J., Bari, R. P., Garmier, M., Eggermont, K., Brouwer, M., Penninckx, I. A. M. A., Broekaert, W. F., and Cammue, B. P. A. 2002. Esal, an Arabidopsis mutant with enhanced susceptibility to a range of necrotrophic fungal pathogens, shows a distorted induction of defense responses by reactive oxygen generating compounds. Plant J. 29:131-140.

Triwitayakorn, K., Njiti, V. N., Iqbal, M. J., Yaegashi, S., Town, C., and Lightfoot, D. A. 2005. Genomic analysis of a region encompassing $Q R f s 1$ and $Q R f s 2$ : Genes that underlie soybean resistance to sudden death syndrome. Genome 48:125-138.

Trotochaud, A. E., Hao, T., Wu, G., Yang, Z., and Clark, S. E. 1999. The CLAVATA1 receptor-like kinase requires CLAVATA3 for its assembly into a signaling complex that includes KAPP and a Rho-related protein. Plant Cell 11:393-406.

Van der Biezen, E. A., and Jones, J. D. 1998. Plant disease-resistance proteins and the gene-for-gene concept. Trends Biochem. Sci. 23:454-456.

van der Hoorn, R. A., Wulff, B. B., Rivas, S., Durrant, M. C., van der Ploeg, A., de Wit, P. J., and Jones, J. D. 2005. Structure-function analysis of cf-9, a receptor-like protein with extracytoplasmic leucine-rich repeats. Plant Cell 17:1000-1015.

Vinagre, F., Vargas C., Schwarcz, K., Cavalcante, J., Nogueira, E. M., Baldani, J. I., Ferreira, P. C., and Hemerly, A. S. 2006. SHR5: A novel plant receptor kinase involved in plant-N2-fixing endophytic bacteria association. J. Exp. Bot. 57:559-569.

Vision, T. J., Brown, D. G., and Tanksley, S. D. 2000. The origins of genomic duplications in Arabidopsis. Science 290:2114-2117.

Walker, J. C., and Zhang, R. 1990. Relationship of a putative receptor protein kinase from maize to the S-locus glycoproteins of Brassica. Nature 345:743-746.

Wang, G. L., Ruan, D. L., Song, W. Y., Sideris, S., Chen, L., Pi, L. Y. Zhang, S., Zhang, Z., Fauquet, C., Gaut, B. S., Whalen, M. C., and Ronald, P. C. 1998. Xa21D encodes a receptor-like molecule with a leucine-rich repeat domain that determines race-specific recognition and is subject to adaptive evolution. Plant Cell 5:765-779.

Wang, Y. S., Pi, L. Y., Chen, X., Chakrabarty, P. K., Jiang, J., De Leon, A. L., Liu, G. Z., Li, L., Benny, U., Oard, J., Ronald, P. C., and Song, W. Y. 2006. Rice Xa21 binding protein 3 is a ubiquitin ligase required for full Xa21-mediated disease resistance. Plant Cell 18:3635-3646.

Wessler, S. R., Bureau, T. E., and White, S. E. 1995. LTR-retrotransposons and MITEs: Important players in the evolution of plant genomes. Curr. Opin. Genet. Dev. 5:814-821.

Yamamoto, E., and Knap, H. T. 2001. Soybean receptor-like protein kinase genes: Paralogous divergence of a gene-family. Mol. Biol. Evol. 18:1522-1531.

Young, J. M., Friedman, C., Williams, E. M., Ross, J. A., Tonnes-Priddy, L., and Trask, B. J. 2002. Different evolutionary processes shaped the mouse and human olfactory receptor gene-families. Hum. Mol. Genet. 11:535-546.

Zapata, J. M., Matsuzawa, S., Godzik, A., Leo, E., Wasserman, S. A., and Reed, J. C. 2000. The Drosophila tumor necrosis factor receptor-associated factor-1 DTRAF1. interacts with Pelle and regulates NFkappaB activity. J. Biol. Chem. 275:12102-12107.

Zhang, X. S., Choi, J. H., Heinz, J., and Chetty, C. S. 2006. Domain-specific positive selection contributes to the evolution of Arabidopsis leucine-rich repeat receptor-like kinase LRR RLK. genes. J. Mol. Evol. 63:612-621. 